\title{
Bilateral pneumonectomy and lung transplant for COVID-19-induced respiratory failure
}

Ali Ghodsizad, MD, PhD, ${ }^{a}$ April A. Grant, MD, ${ }^{b}$ Asif N. Mohammed, MD, ${ }^{c}$ Jose Navas-Blanco, MD, ${ }^{c}$ Arjang Ruhparwar, MD, PhD, ${ }^{\mathrm{d}}$ Mehdi Mirsaeidi, MD, ${ }_{\mathrm{e}}^{\mathrm{e}}$ Joshua M. Hare, MD, ${ }_{\mathrm{f}}^{\mathrm{f}}$ Eduardo DeMarchena, MD, ${ }^{\mathrm{f}}$ and Matthias Loebe, MD, PhD, ${ }^{\mathrm{a}}$ Miami, Fla; Atlanta, Ga; and Essen, Germany

\footnotetext{
From the ${ }^{\mathrm{a} D i v i s i o n}$ of Cardiothoracic Surgery, Dewitt Daughtry Family Department of Surgery, and ${ }^{\mathrm{c}}$ Department of Anesthesiology, Perioperative Medicine and Pain Management, and Divisions of ${ }^{\mathrm{e}}$ Pulmonary Critical Care and ${ }^{\mathrm{f} C a r d i o l o g y}$, University of Miami, Leonard M. Miller School of Medicine, Miami, Fla; ${ }^{\mathrm{b}}$ Department of Surgery, Emory University School of Medicine and Grady Hospital, Atlanta, Ga; and ${ }^{\mathrm{d}}$ Department of Thoracic and Cardiovascular Surgery, University Hospital Essen, Essen, Germany.

Disclosures: The authors reported no conflicts of interest.

The Journal policy requires editors and reviewers to disclose conflicts of interest and to decline handling or reviewing manuscripts for which they may have a conflict of interest. The editors and reviewers of this article have no conflicts of interest.

Received for publication April 4, 2021; accepted for publication Jan 12, 2022; available ahead of print Jan 21, 2022.

Address for reprints: Ali Ghodsizad, MD, PhD, Division of Cardiothoracic Surgery, University of Miami, Leonard M. Miller School of Medicine, 1801 NW 9th Ave, 6th Floor, Miami, FL 33136 (E-mail: axg1433@ miami.edu). JTCVS Techniques 2022;13:282-7

2666-2507

Copyright $(2022$ The Author(s). Published by Elsevier Inc. on behalf of The American Association for Thoracic Surgery. This is an open access article under the CC BY-NC-ND license (http://creativecommons.org/licenses/bync-nd/4.0/).

https://doi.org/10.1016/j.xjtc.2022.01.019
}

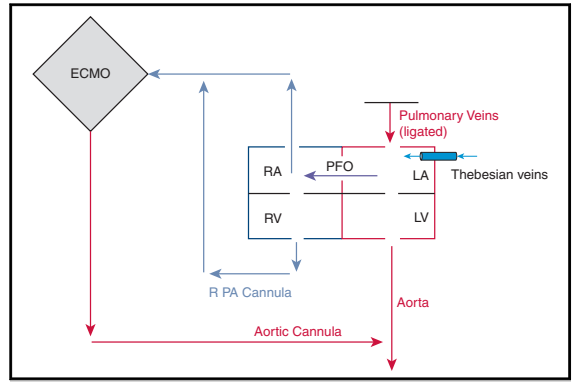

Novel cannulation strategy used for cardiopulmonary support after bilateral pneumonectomy.

\section{CENTRAL MESSAGE \\ Bilateral pneumonectomy with a novel cannulation strategy fol- lowed by lung transplantation can be a rescue measure for those patients with severe, irre- versible lung damage caused by SARS-COV-2.}

See Commentary on page 288.
There are few published descriptions of lung transplant for COVID-19 (Table E1). Here, we describe a COVID-19 polymerase chain reaction (PCR) test-positive patient who underwent bilateral pneumonectomy before lung transplant using a novel cannulation strategy. Institutional review board approval was not required for this case study and the patient provided consent.

A 37 year-old woman was admitted with COVID-19 infection required intubation on day 6 , and venovenous (VV) extracorporeal membrane oxygenation (ECMO) on day 8. She was treated for Stenotrophomonas superinfection. On day 20, she was enrolled in a trial for application of stem cells via the ECMO circuit, which occurred without complication. For the next several weeks, she required full ECMO with an inability to wean. On day 37 , due to persistent positivity (based on PCR test), a cycle threshold $(\mathrm{Ct})$ was obtained and resulted at 30, indicating she may still have a high viral load, ${ }^{1}$ which could complicate transplantation. We elected to perform pneumonectomy before transplant to reduce or eliminate the viral reservoir. She was listed for transplant on day 39, and 3 days later underwent bilateral pneumonectomy at which time her VV ECMO was converted to central venoarterial ECMO using a novel cannulation strategy taking advantage of the patient's known patent foramen ovale (PFO). Venous drainage occurred with 3 cannulas: 1 via the right internal jugular vein and 1 from the left femoral vein. The third cannula was placed in the right pulmonary artery (PA). All blood was returned to a single ECMO device using Y-connectors. The blood was then returned to the patient via an arterial cannula into the ascending aorta. Filling of the left heart occurred primarily from the Thebesian veins (Figure 1). Postoperative echocardiogram demonstrated a decompressed right and left ventricle. There was no evidence of mitral regurgitation and even with the left to right shunt induced by ECMO and the PFO, the left ventricle did fill and was able to expel blood into the aorta with inotropic 


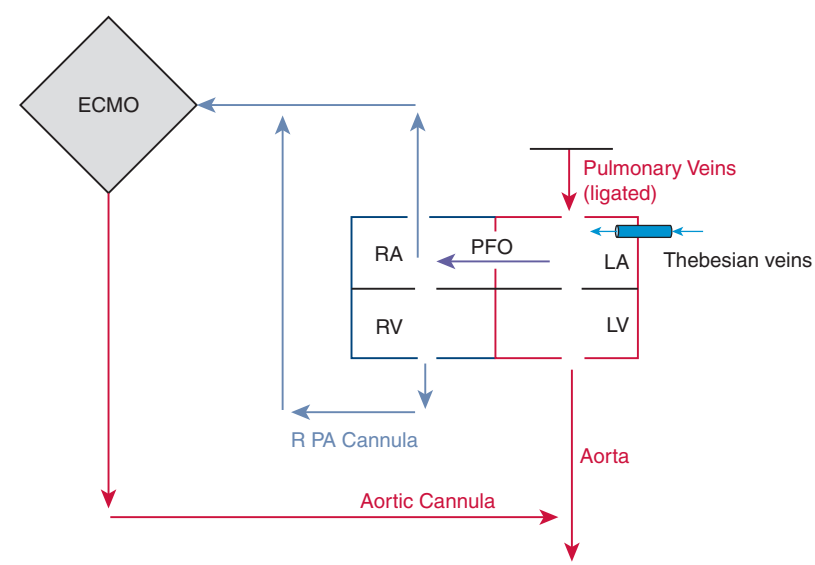

FIGURE 1. Novel cannulation strategy used for cardiopulmonary support after bilateral pneumonectomy. ECMO, Extracorporeal membrane oxygenation; $R A$, right atrium; $P F O$, patent foramen ovale; $L A$, left atrium; $R V$, right ventricle; $L V$, left ventricle; $P A$, pulmonary artery.

support. Her chest was closed on postoperative day 2. On day 48 , donor lungs were found. The left lung was not appropriate for transplantation but fortunately the right lung was oversized. Based on the length of time she had been on ECMO and now 5 days after bilateral pneumonectomy, the multidisciplinary team believed it was prudent to proceed with single lung transplant. She was converted to VV ECMO and her PA cannula was removed. She tolerated routine postoperative immunosuppression and no additional antiviral therapy was added. Her posttransplant PCR test result converted to negative and remained so (Table 1). She was decannulated from ECMO approximately 8 weeks after transplant. Six months posttransplant, she was alert and oriented, off mechanical ventilation, and debilitated but participating in rehabilitation.

Substituting the lungs with mechanical support requires a thoughtful strategy that prevents stasis and distention of the heart. Ligation of the PA removes the right heart outlet, and ligation of the pulmonary veins compromises left heart preload. We maintained flow across the right heart by inserting a cannula into the right PA to allow for right ventricle ejection and reduce afterload. For the left heart, we relied on the Thebesian veins for preload. After months of critical illness and refractory hypoxia, our patient's left heart function was reduced with an ejection fraction $<40 \%$, leading to concern about the ability of the left ventricle to maintain adequate ejection. Her PFO provided a strategy by which we could unload the left ventricle, and allow for flow in the left atrium by creating a left to right shunt. Two other strategies for ECMO cannulation after bilateral pneumonectomy are described in the literature (Figure 2 and Video 1). Cypel and colleagues $^{2}$ utilized 2 ECMO circuits to accomplish flow in all 4 chambers, and Barac and colleagues ${ }^{3}$ modified native anatomy by anastomosing the left PA to the left pulmonary vein to accomplish the same goal. The advantages of our strategy are 2-fold. First, only 1 ECMO device is utilized reducing the risk of thrombosis and hemolysis. Second, it is technically simpler; that is, no anastomosis. This model could be replicated in patients without a PFO by performing atrial septostomy at the time of the pneumonectomy. ${ }^{1}$ In our patient, PFO closure at the time of transplant was deferred due to adequate PA pressures.

TABLE 1. Reverse transcription polymerase chain reaction (PCR) results over time

\begin{tabular}{|c|c|c|}
\hline Hospital day & PCR test result & Event \\
\hline Day 21 & Positive & \\
\hline Day 34 & Positive & \\
\hline Day 39 & & Bilateral pneumonectomy \\
\hline Day 42 & Positive* & \\
\hline Day 45 & & Single lung transplant \\
\hline Day 46 & Negative & \\
\hline Day 49 & Negative & \\
\hline Day 51 & Negative & \\
\hline Day 54 & Negative & \\
\hline Day 56 & Negative & \\
\hline Day 59 & Negative & \\
\hline Day 61 & Negative & \\
\hline Day 62 & Negative & \\
\hline
\end{tabular}

*The patient turned negative immediately following her single lung transplant. We do not believe this is a result of receiving her single lung transplant, but rather the result of her bilateral pneumonectomy 5 days prior. She did have 1 PCR performed after pneumonectomy that was positive, but we do not have cycle threshold data on this specimen and cannot determine its significance. 


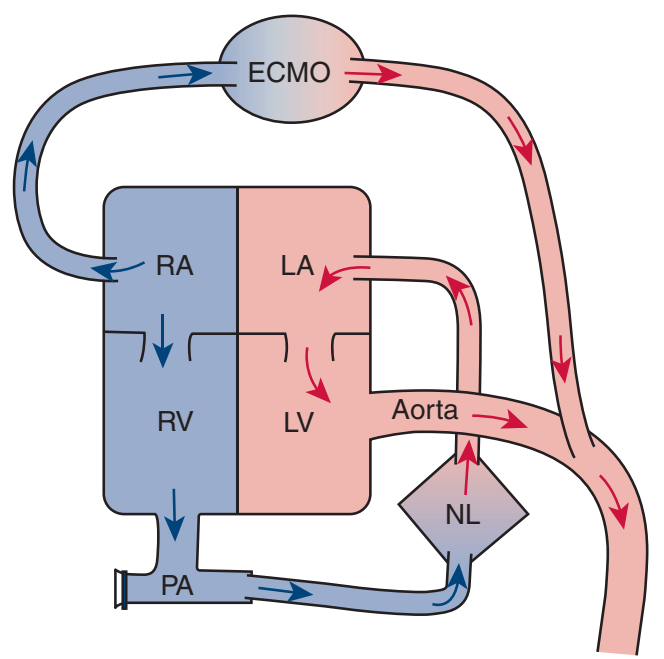

A

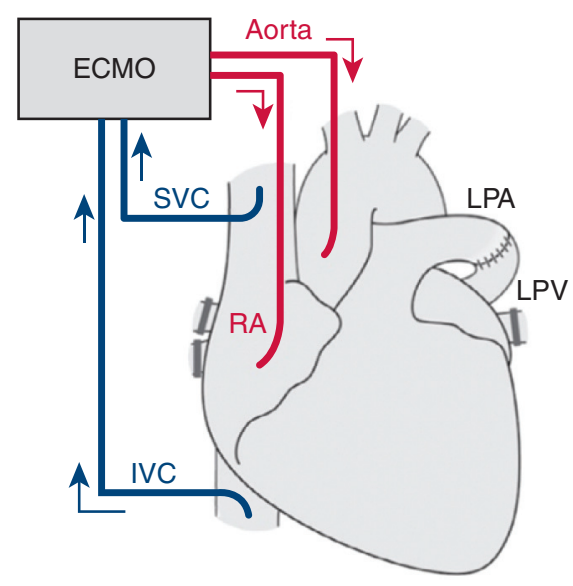

B

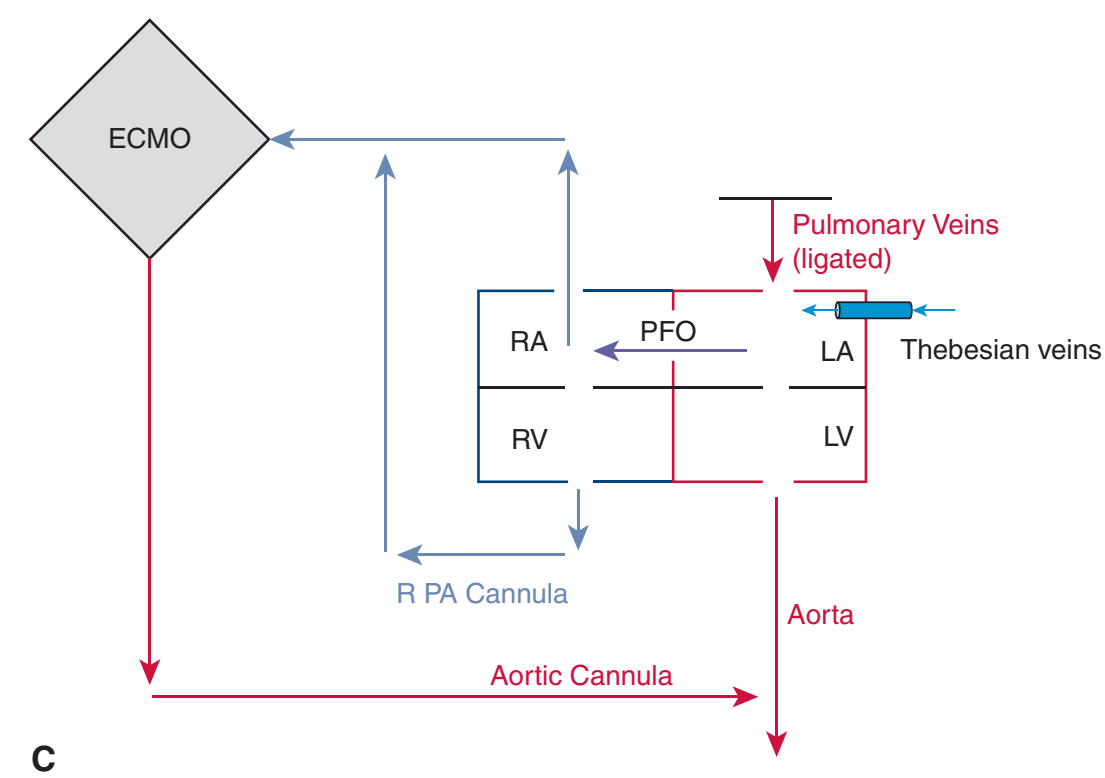

FIGURE 2. Diagram illustrating the 3 published techniques for mechanical support following bilateral pneumonectomy. A, Reprinted from Cypel and colleagues. ${ }^{2}$ Used with permission. B, Reprinted from Barac and colleagues. ${ }^{3}$ Used with permission. C, Technique described by our treatment team utilizing the native patent foramen ovale (PFO) to ensure flow through the left atrium $(L A)$. ECMO, Extracorporeal membrane oxygenation; $R A$, right atrium; $R V$, right ventricle; $L V$, left ventricle; $P A$, pulmonary artery.

$\mathrm{Ct}$ is used to describe viral load with counts $<25$ indicative of a high viral load, and counts $>31$ indicative of low viral load. ${ }^{4}$ Results between 25 and 30 may indicate active ongoing infection. Her $\mathrm{Ct}$ results, coupled with her dismal clinical status, led to the strategy of bilateral pneumonectomy first, as has been described in cystic fibrosis patients. $^{2,3}$
Based on our experience, patients with COVID-19 requiring ECMO for 4 to 6 weeks with no signs of recovery should be considered for transplant. Additionally, if they show signs of persistent viral infection, pneumonectomy before transplant may be the preferred strategy. More study is needed to determine which patients would benefit, particularly at a time when resources are of paramount importance. 

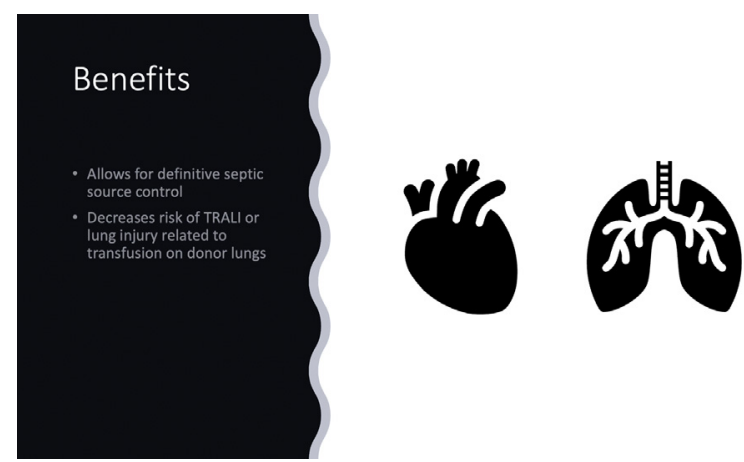

\section{References}

1. Prasad A, Ghodsizad A, Brehm C, Kozak M, Koerner M, El Banayosy A, et al. Refractory pulmonary edema and upper body hypoxemia during veno-arterial extracorporeal membrane oxygenation-a case for atrial septostomy. Artif Organs. 2018;41:664-9.

2. Cypel M, Waddell T, Singer LG, del Sorbo L, Fan E, Binnie M, et al. Bilateral pneumonectomy to treat uncontrolled sepsis in a patient awaiting lung transplantation. J Thorac Cardiovasc Surg. 2017;153:e67-9.

3. Barac YD, Bryner B, Bonadonna D, Wolfe C, Reynods J, Haney J, et al. Bilateral pneumonectomy with veno-arterial extracorporeal membrane oxygenation as a bridge to lung transplant. J Heart Lung Transplt. 2019;38:1231-2.

4. Rabaan AA, Tirupathi R, Sule AA, Aldali J, Mutair AA, Alhumaid S, et al. Viral dynamics and real time RT-PCR Ct values correlate with disease severity in COVID-19. Diagnostics. 2021;11:1091-109.

VIDEO 1. Brief description of the indications, benefits, and challenges of extracorporeal membrane oxygenation after bilateral pneumonectomy as well as a comparison of 3 described cannulation strategies. Video available at: https://www.jtcvs.org/article/S2666-2507(22)00050-5/fulltext. 


\section{E-References}

E1. Chen JY, Qiao K, Liu F, Wu B, Xu X, Jiao G-Q, et al. Lung transplantation as therapeutic option in acute respiratory distress syndrome for coronavirus disease 2019-related pulmonary fibrosis. Chin Med J. 2020;133:1390-6.

E2. Han W, Zhu M, Chen J, Zhang J, Zhu S, Li T, et al. Lung transplantation for elderly patients with end-stage COVID-19 pneumonia. Ann Surg. 2020;272:e33-4.

E3. Lang C, Jaksch P, Hoda MA, Lang G, Staudinger T, Tschernko E, et al. Lung transplantation for COVID-19-associated acute respiratory distress syndrome in a PCR-positive patient. Lancet Respir Med. 2020;8:1057-60.

E4. Bharet A, Querrey M, Markov NS, Kim S, Kurihara C, Garza-Castillon R, et al. Lung transplantation for patients with severe COVID-19. Sci Transl Med. 2020; 12:eabe4282. 
TABLE E1. Published descriptions of lung transplant for COVID-19

\begin{tabular}{|c|c|c|c|c|c|c|c|}
\hline Author & Location & $\begin{array}{c}\text { Date of } \\
\text { publication }\end{array}$ & $\begin{array}{c}\text { No. of } \\
\text { patients }\end{array}$ & $\begin{array}{r}\text { Days from } \\
\text { infection to } \\
\text { transplant }\end{array}$ & $\begin{array}{c}\text { Preoperative } \\
\text { PCR status }\end{array}$ & Technique & Survival $(\%)$ \\
\hline Chen and colleagues ${ }^{\mathrm{E} 1}$ & China & June 2020 & 3 & $42,37,44$ & Negative & Bilateral lung & 66 \\
\hline Han and colleagues ${ }^{\mathrm{E} 2}$ & China & August 2020 & 2 & 30,28 & Negative & Bilateral lung & 100 \\
\hline Lang and colleagues ${ }^{\mathrm{E} 3}$ & Vienna, Austria & August 2020 & 1 & 58 & Positive & Bilateral lung & 100 \\
\hline Bharat and colleagues $^{\mathrm{E} 4}$ & $\begin{array}{l}\text { United States } \\
\text { (Chicago, Ill) }\end{array}$ & December 2020 & 3 & $42,100,28$ & Negative & Bilateral lung & 100 \\
\hline $\begin{array}{l}\text { Ghodsizad and colleagues } \\
\text { (current study) }\end{array}$ & $\begin{array}{l}\text { United States } \\
\text { (Miami, Fla) }\end{array}$ & - & 1 & 48 & Positive & $\begin{array}{r}\text { Bilateral pneumonectomy/ } \\
\text { ECMO } \longrightarrow>\text { single lung }\end{array}$ & 100 \\
\hline
\end{tabular}

$P C R$, Polymerase chain reaction; ECMO, extracorporeal membrane oxygenation. 